\title{
QUEEN'S
UNIVERSITY
BELFAST
}

\section{Transepithelial nasal potential difference in patients with, and at risk of acute respiratory distress syndrome}

MacSweeney, R., Reddy, K., Davies, J. C., Parker, M., Kelly, B., Elborn, J. S., Conlon, J., Verghis, R. M., Calfee, C. S., Matthay, M. A., Alton, E. WFW., \& McAuley, D. (2021). Transepithelial nasal potential difference in patients with, and at risk of acute respiratory distress syndrome. Thorax. https://doi.org/10.1136/thoraxjnl-2020215587, https://doi.org/10.1136/thoraxjnl-2020-215587

\section{Published in:}

Thorax

\section{Document Version:}

Peer reviewed version

\section{Queen's University Belfast - Research Portal:}

Link to publication record in Queen's University Belfast Research Portal

\section{Publisher rights}

Copyright 2021 BMJ. This manuscript is distributed under a Creative Commons Attribution-NonCommercial-NoDerivs License

(https://creativecommons.org/licenses/by-nc-nd/4.0/), which permits distribution and reproduction for non-commercial purposes, provided the author and source are cited.

\section{General rights}

Copyright for the publications made accessible via the Queen's University Belfast Research Portal is retained by the author(s) and / or other copyright owners and it is a condition of accessing these publications that users recognise and abide by the legal requirements associated with these rights.

Take down policy

The Research Portal is Queen's institutional repository that provides access to Queen's research output. Every effort has been made to ensure that content in the Research Portal does not infringe any person's rights, or applicable UK laws. If you discover content in the Research Portal that you believe breaches copyright or violates any law, please contact openaccess@qub.ac.uk. 


\title{
respiratory distress syndrome
}

\author{
Rob MacSweeney ${ }^{1,2} \mathrm{PhD}$ \\ Kiran Reddy ${ }^{3,4} \mathrm{MB}$ \\ Jane C. Davies ${ }^{5,6}$ MD \\ Mike Parker ${ }^{7}$ Cstat \\ Barry Kelly ${ }^{1} \mathrm{MD}$ \\ J. Stuart Elborn² MD \\ John Conlon² BSc \\ Rejina M. Verghis ${ }^{2}$ MSc \\ Carolyn S. Calfee ${ }^{8,9} \mathrm{MD}$ \\ Michael A. Matthay ${ }^{8}$ MD \\ Eric WFW. Alton ${ }^{5,6}$ FMedSci \\ Daniel F. McAuley ${ }^{1,2}$ MD
}

${ }^{1}$ Royal Victoria Hospital, 274 Grosvenor Road, Belfast, BT12 6BA

${ }^{2}$ Wellcome-Wolfson Institute for Experimental Medicine, School of Medicine,

Dentistry and Biomedical Sciences, Queen's University Belfast, 97 Lisburn Rd,

Belfast BT9 7BL

${ }^{3}$ Department of Anaesthesia, Intensive Care, and Pain Medicine, Mater

Misericordiae University Hospital, Eccles St, Northside, Dublin 7, D07 R2WY

${ }^{4}$ University College Dublin, Belfield, Dublin 4

${ }^{5}$ National Heart and Lung Institute, Imperial College, London, England

${ }^{6}$ Royal Brompton \& Harefield Foundation Trust, London, England

${ }^{7}$ Anglia Ruskin University, Chelmsford, England

${ }^{8}$ Department of Medicine, Division of Pulmonary, Critical Care, Allergy and Sleep

Medicine; University of California, San Francisco, San Francisco, CA

${ }^{9}$ Department of Anesthesia; University of California, San Francisco, San Francisco, $\mathrm{CA}$ 


\section{Location:}

This work was performed at the Royal Victoria Hospital, Belfast and Belfast City Hospital, Northern Ireland.

\section{Financial Support:}

Northern Ireland Public Health Agency, Research and Development Division;

Intensive Care Society of Ireland.

\section{MeSH Terms:}

Acute respiratory distress syndrome; acute lung injury, nasal potential difference, transmembrane electrical potential difference

\section{Corresponding Author:}

Prof. Danny McAuley (d.f.mcauley@qub.ac.uk)

\section{Word Count:}

Abstract: 271

Main text: 3574 


\section{Abstract}

\section{Background}

Impaired alveolar fluid clearance, determined in part by alveolar sodium transport, is associated with acute respiratory distress syndrome (ARDS). Nasal sodium transport may reflect alveolar transport. The primary objective of this prospective, observational study was to determine if reduced nasal sodium transport, as measured by nasal potential difference (NPD), was predictive of the development of and outcome from ARDS.

\section{Methods}

NPD was measured in 15 healthy controls and in 88 patients: 40 mechanically ventilated patients defined as "at-risk" for ARDS, 61 mechanically ventilated patients with ARDS (13 who were previously included in the 'at-risk" group), and 8 ARDS survivors on the ward.

\section{Results}

In at-risk subjects, maximum NPD (mNPD) was greater in those who developed ARDS (difference -8.4 mV; 95\% Cl: -13.8, -3.7; $\mathrm{p}=0.005$ ) and increased mNPD predicted the development of ARDS before its onset (AUC $0.75 ; 95 \% \mathrm{Cl}: 0.59,0.89$ ). In the ARDS group, mNPD was not significantly different for survivors and nonsurvivors $(p=0.076)$, and mNPD was a modest predictor of death (AUC $0.60 ; 95 \% \mathrm{Cl}$ : $0.45,0.75) . m N P D$ was greater in ARDS subjects $(-30.8 \mathrm{mV})$ than in at-risk subjects $(-24.2 \mathrm{mV})$ and controls $(-19.9 \mathrm{mV})(\mathrm{p}<0.001)$. NPD values were not significantly different for survivors and controls $(p=0.18)$.

\section{Conclusions}

Increased NPD predicts the development of ARDS in at-risk subjects but does not predict mortality. NPD increases before ARDS develops, is greater during ARDS, but 
is not significantly different for controls and survivors. These results may reflect the up-regulated sodium transport necessary for alveolar fluid clearance in ARDS. NPD may be useful as a biomarker of endogenous mechanisms to stimulate sodium transport. Larger studies are now needed to confirm these associations and predictive performance. 


\section{Key messages}

\section{What is the key question?}

Are patients with low nasal epithelial sodium transport, as measured by NPD, more likely to develop ARDS?

\section{What is the bottom line?}

Contrary to the hypothesis, a higher NPD predicted ARDS development, which may reflect a physiological response to upregulate sodium transport in response to pulmonary oedema or the clinical conditions that are associated with the development of ARDS. Larger studies are now needed to confirm these associations and predictive performance.

\section{Why read on?}

Upper respiratory epithelial sodium transport, as measured by NPD, is increased in ARDS and does not differ between ARDS survivors and controls.

Although a low NPD is associated with the development of pulmonary oedema in the setting of neonatal respiratory distress syndrome and high altitude pulmonary oedema, this study found the opposite result in ARDS. Measurement of NPD may have a role in identifying at-risk patients who would progress to develop ARDS. 


\section{Introduction}

The resolution of non-cardiogenic pulmonary oedema in the setting of the acute respiratory distress syndrome (ARDS) is dependent on active alveolar epithelial sodium transport. ${ }^{1}$ The alveolar cell $\mathrm{Na}^{+} / \mathrm{K}^{+}$ATPase creates a concentration gradient for sodium and an osmotic gradient for water to move from the alveolus into the interstitium. Sodium moves through the apical membrane predominantly via the epithelial sodium channel $(\mathrm{ENaC})$ and is actively transported through the basolateral membrane. ${ }^{2}$ Inhibition of $\mathrm{ENaC}$, via amiloride, reduces alveolar fluid clearance (AFC) and potentiates pulmonary oedema. ${ }^{1} \mathrm{AFC}$ is significantly reduced in the majority of ARDS patients, suggesting that alveolar sodium transport may be affected. ${ }^{3}$

Fine balance of sodium absorption and chloride secretion controls the respiratory tract fluid volume,${ }^{4}$ and is required for normal nasal ${ }^{5}$, airway ${ }^{6}$ and alveolar function. ${ }^{7}$ The differential distribution of sodium and chloride across cell membranes creates a voltage, or potential difference (PD). In the diagnosis of cystic fibrosis, the measurement of nasal epithelial ion transport is used as a non-invasive surrogate measure of airway epithelial ion transport. ${ }^{8}$ Maximum nasal PD (the most negative nasal potential difference [mNPD]) is in part reflective of sodium transport, with the luminal electrode recording a negative voltage relative to the interstitium. ${ }^{9}$ By perfusing the nasal epithelium with amiloride, a specific $\mathrm{ENaC}$ inhibitor, a measure of the contribution of this ion channel to total sodium transport, termed the amiloride response, can be made. Although the alveolus is the site of interest in the development of pulmonary oedema, the measurement of alveolar PD is highly invasive. NPD measurement is well tolerated and has been shown to correlate with the PD found in the distal respiratory epithelium. .10 
Studies using NPD have implicated dysfunctional respiratory epithelial sodium transport in the pathogenesis of two forms of non-cardiogenic pulmonary oedema: neonatal respiratory distress syndrome (RDS) ${ }^{11,12}$ and high altitude pulmonary oedema (HAPE) ${ }^{13-16}$, where decreased (less negative) NPD was associated with the development of these conditions. Transgenic mice with poorly functional ENaC demonstrated reduced NPD and were otherwise healthy until exposed to thioureainduced pulmonary oedema, when they suffered worse lung injury and reduced AFC in comparison to wild type mice. NPD and AFC were highly correlated. ${ }^{17}$ These data suggest NPD may be a surrogate for alveolar fluid transport. Since non-cardiogenic pulmonary oedema is a hallmark of ARDS, constitutively reduced alveolar fluid transport may be an independent risk factor for ARDS development and poor outcome from the syndrome.

On this basis, we investigated lower mNPD for its usefulness as a clinical tool to predict the development of ARDS in "at-risk" patients and to predict ARDS mortality. We hypothesised that critically ill, mechanically ventilated patients with a risk factor for ARDS and lower mNPD, would be more likely to develop ARDS than those patients with an ARDS risk factor and higher mNPD. We also tested the hypothesis that decreased mNPD would predict mortality from ARDS in patients diagnosed with the syndrome. 


\section{Materials and methods}

This was a multi-centre prospective observational study that was conducted in two NHS hospitals (Royal Victoria Hospital and Belfast City Hospital) from 20102011. The local research ethics committee approved the study and all subjects, or their representative, gave written informed consent. Measurements were obtained in the following subjects (Table 1): 1) critically ill mechanically ventilated patients at-risk for the development of ARDS ("at-risk"); 2) critically ill mechanically ventilated patients with ARDS ("ARDS"), 13 of whom had previously been included in the "atrisk" group; 3) patients who survived ARDS ("survivors"), 7 of whom who had been previously included in the "ARDS" group; and 4) healthy controls ("controls"). (Figure 1) Where possible, subjects underwent serial measurements, such that a patient could be included in any, or all, of the at-risk, ARDS, and survivor groups. A single person could be considered as a distinct subject in each of the 1) at-risk, 2) ARDS and 3) survivor groups, although repeat measurements on the same subjects were excluded from inter-group comparative analyses to maintain statistical integrity. Categorization of critically ill patients into either the at-risk or ARDS group was by American-European Consensus Conference (AECC) criteria. ${ }^{18}$ On re-evaluation, all cases were scored by the current Berlin definition. ${ }^{19}$ Allocation to the at-risk or ARDS group was performed after subjects had their NPD measured in order to maintain investigator blinding. At-risk patients were screened daily for the development of ARDS every day while mechanically ventilated in ICU. Measurement of NPD in survivors was performed at a timepoint when clinical recovery was sufficient and when capacity to consent to the procedure had recovered.

The inclusion criteria varied according to group and for the at-risk group were patients with a risk factor for the development of ARDS (Table 1) ${ }^{20}$, within 24 hours 
of commencement of invasive mechanical ventilation; for the ARDS group were patients receiving invasive mechanical ventilation within 24 hours of the development of ARDS; and for the survivor group were patients who previously had ARDS and survived to ICU discharge; and healthy controls. Exclusion criteria for all cohorts were age less than 18, pregnancy, period of ventilation likely to be less than 24 hours, cardiac failure, patients unlikely to survive 24 hours, cystic fibrosis, nasal injury, skull base fracture and upper respiratory tract infection; for the survivor group, the requirement for supplemental oxygen or other new pulmonary therapy, such as antimicrobial agents directed at a pulmonary source or bronchodilators.

\section{Measurements}

Subjects had demographics, physiological variables, development of ARDS, duration of ventilation and mortality recorded. Follow up was until death or discharge/transfer from hospital.

\section{Nasal potential difference measurement technique}

Pilot work demonstrated that repeated passage of the NPD catheter altered the NPD value recorded. Therefore NPD was measured using a modified standard technique $^{21}$ (see Supplemental Materials).

Briefly, an exploring electrode (Marquat Génie Biomédical, France) connected to a voltmeter (LoganSinclair Scientific, England) via an electrode (neuroline cup, Ambu, Denmark) was inserted into the nasal passage, while a reference electrode was secured over an area of abraded skin on the forearm. Sodium specific components of the NPD reading were performed by this technique (mNPD and amiloride response). The site of most negative NPD was found and the catheter was 
fixed at this point. The catheter was reinserted, again locating the site of most negative NPD. This process was repeated for 30 minutes totalling 10 insertions. The most negative stable value $( \pm 0.5 \mathrm{mV}$ for 30 seconds) was recorded as $\mathrm{mNPD}$.

\section{Diagnosis of the acute respiratory distress syndrome}

A single consultant radiologist, who was blinded to the patient's clinical status and the result of the NPD reading, interpreted all chest radiographs for the presence of bilateral infiltrates. Based on this radiological categorization, in conjunction with the other $A E C C$ criteria ${ }^{18}$, subjects were designated as being in either the at-risk or ARDS groups. On re-evaluation, ARDS diagnosis was scored by the current Berlin definition. ${ }^{19}$

\section{Sample size calculations}

A clinically significant difference of $8.2 \mathrm{mV}$ in baseline NPD measurement has previously been shown to predict subjects at risk of developing high altitude pulmonary oedema. ${ }^{16}$ From this data, the pooled standard deviation for controls and at-risk subjects was $7.7 \mathrm{mV}$.

Prospective sample size calculations to relate NPD measurement to development of and mortality from ARDS were performed with PASS software (NCSS LLC, Kaysville, UT, USA) using simplified predictive logistic models.

For the primary outcome, to use NPD measurement to predict the development of ARDS, a sample size of 155 patients at risk of ARDS was required to achieve a power of $80 \%$ when applying a test for the fit of the logistic model using a $5 \%$ significance test. To predict mortality from ARDS, a sample size of 60 subjects 
with ARDS was necessary to achieve $80 \%$ power using a test for the fit of the logistic model at a $5 \%$ significance threshold.

For the secondary outcome of investigating nasal sodium transport in different states of health, 15 subjects per group were required to detect a between-group difference of $8.2 \mathrm{mV}$ using a two-sided two-sample t-test, at a $5 \%$ significance level with $80 \%$ power. This calculation was performed using nQuery Advisor version 6.01 (Statistical Solutions Ltd., Boston, MA, USA).

\section{Statistics}

Statistical analysis was performed using $R$ software ( $R$ Foundation for Statistical Computing, Vienna, Austria). Inter-group analyses were performed only on mutually exclusive groups. For the inter-group analyses, the 13 subjects who underwent sequential NPD readings while at-risk and later with ARDS are included in the at-risk group but excluded from the ARDS group. This was done to avoid mixing paired and unpaired measurements in a single hypothesis test. All subjects in a group are included in intra-group analyses. Variables selected for logistic regression were chosen based on clinical importance and known association with outcome in ARDS. The capacity of NPD to predict outcome was assessed with receiver operator characteristic curves, with the optimum cut-off point being determined according to the maximum Youden Index. Comparative analyses were determined using permutation tests with bootstrapping to estimate the standard error of the mean (SEM) and 95\% confidence limits (CL), applying the Dunn-Sidak adjustment for multiplicity. Correlations were analysed with Pearson correlation coefficient, with bootstrapped $95 \% \mathrm{CL}$ and $\mathrm{p}$-values determined by permutation testing. 3-group comparison between controls, at-risk subjects, and ARDS subjects 
was by permutation test for one-way analysis of variance with bootstrapped $95 \%$ confidence limits using the Dunn-Sidak adjustment for multiplicity. Results are presented as mean (standard deviation) unless specified. A p-value $<0.05$ was considered to be statistically significant. Further details are provided in the supplemental materials.

NPD was deemed to have "modest" predictive value if the area under the receiver operating curve $(A \cup C)$ was $0.60-0.70$. The threshold chosen for "fair" predictive value was $0.70 \leq A \cup C \leq 0.80$. "Good" predictive value was defined as $0.80 \leq A \cup C \leq 0.90$ and "excellent" predictive value was defined as $0.90 \leq A \cup C \leq 1.0$.

\section{$\underline{\text { Results }}$}

\section{Patient characteristics}

Of 520 critically ill patients screened, 95 were recruited. Of those, 88 were included and completed data collection. The three most common reasons for exclusion were: expected ventilation <24 hours, no risk factor for ARDS, and heart failure. Measurements were made on 15 healthy controls, and 88 patients (40 whilst 'at-risk'; 61 diagnosed with ARDS, of whom 13 had been included in the 'at risk' group). Eight subjects who survived ARDS had their NPD re-measured on the ward after discharge from ICU; 7 of these had ARDS time-point NPD whilst one only had an 'at risk' time point (Figure 1). The funding period ended before the planned number of "at-risk" patients were recruited.

The at-risk and ARDS subjects underwent NPD measurements within a mean of 17 (7) hours and 11 (8) hours respectively of meeting study inclusion criteria. NPD readings in the survivor group were undertaken 16 (16) days after admission to ICU. 
The baseline demographics and clinical parameters of the study subjects are given in Table 1. Pneumonia and non-pulmonary sepsis were the most common ARDS risk factors.

Twenty four of the 40 at-risk subjects (60\%) developed ARDS after a mean of 85 (47) hours after admission to the ICU. In the at-risk group, the mean duration of ventilation was 9 (7) days in the entire group, 4 (4) days in those who did not develop ARDS, and 12 (7) days in those who did develop ARDS. In the ARDS group the mean duration of ventilation was 12 (11) days in the entire group, 12 (11) days in those who survived and 14 (11) days in those who died. Eleven of the 40 at risk subjects $(27.5 \%)$ and 23 of the 61 ARDS subjects (37.7\%) died.

\section{Predictive capacity of nasal potential difference}

In the at-risk group, using binary logistic regression, NPD was the only single predictor of the development of ARDS, with those patients who developed ARDS having increased (more negative) mNPD before ARDS development (Table 2). The area under the curve was 0.75 (95\% CL: $0.59,0.89)$, indicating fair overall predictive value, with a cut-off of $-32.4 \mathrm{mV}$ having a sensitivity of $41.7 \%$ (95\% CL: $24.5,61.1)$, specificity of $100 \%$ (95\% CL: $80.6,100)$, positive predictive value of $100 \%(95 \% \mathrm{Cl}$ : $\mathrm{NA})$ and negative predictive value of $53.3 \%(95 \% \mathrm{Cl}: 35.2,70.8)$. When patients with traumatic brain injury $(\mathrm{TBI})$ and subarachnoid haemorrhage $(\mathrm{SAH})$ as a risk factor for ARDS were excluded, the AUC was $0.83(95 \% \mathrm{Cl}$ : $0.77,0.97)$.

In the ARDS group, using binary logistic regression, no variables were useful single predictors of mortality (Table 2). The predictive capacity of NPD for mortality in those with ARDS was modest, with AUC of 0.60 (95\% CL: $0.45,0.75)$. A cut-off of $36.6 \mathrm{mV}$ had a sensitivity of $43.5 \%$ (95\% CL: $25.6,63.2)$ and specificity $86.8 \%$ (95\% 
CL: 72.7, 94.2) for mortality. When patients with TBI and SAH were excluded, AUC was $0.64(95 \% \mathrm{Cl}: 0.41,0.87)$.

\section{Nasal potential difference measurements of sodium transport in different states of health}

The summary values of NPD measurements are presented in Table 3, and an example reading is presented in the supplemental materials (Figure S1). Inter-group analyses were performed only on mutually exclusive groups. For the inter-group analyses, the 13 subjects who underwent sequential NPD readings while at-risk and later with ARDS are included in the at-risk group but excluded from the ARDS group. All subjects in a group are included in intra-group analyses.

\section{Nasal potential difference is highest in patients with ARDS}

Maximum NPD was -19.9 (5.7) $\mathrm{mV}$ in control subjects $(\mathrm{n}=15),-24.2(9.5) \mathrm{mV}$ in at-risk subjects $(n=40)$ and $-30.8(9.8) m V$ in ARDS subjects $(n=48)$ (Figure 2). Differences between the at-risk group and the ARDS group (98.3\% CL 1.77, 10.93), as well as between the control group and the ARDS group reached statistical significance $(98.3 \% \mathrm{CL} 4.27,16.79)(p<0.001)$. The control group and the overall atrisk group were not significantly different $(98.3 \% \mathrm{CL}-1.90,10.73)$. In the at-risk group, $24 / 40(60 \%)$ patients were on vasopressors or inotropes at the time of NPD measurement, while 16/40 (40\%) were not. Maximum NPD was not significantly different for patients on and off vasopressors/inotropes at -24.4 (10.1) $\mathrm{mV}$ and -23.7 (8.8) $\mathrm{mV}$, respectively ( $p=0.8)$. In the ARDS group, 32/61 (52\%) patients were on vasopressors or inotropes at the time of NPD measurement while 29/61 (48\%) were 
not. Maximum NPD was not significantly different for patients on and off vasopressors/inotropes at $-32.9(9.6) \mathrm{mV}$ and $-28.5(9.8) \mathrm{mV}$, respectively $(\mathrm{p}=0.08) . "$

The amiloride response was not significantly different between groups; $\mathrm{p}=0.39$. NPD values (difference $4.3 \mathrm{mV}, 95 \% \mathrm{CL}:-2.8,10.5 ; \mathrm{p}=0.18$ ) and amiloride responses (difference $0.2 \mathrm{mV}, 95 \% \mathrm{CL}:-4.1,4.9 ; \mathrm{p}=0.95$ ) were not significantly different between survivors $(n=8)$ and controls $(n=15)$.

In at-risk patients, mNPD was $-8.4 \mathrm{mV}(95 \% \mathrm{CL}:-13.8,-3.7 ; \mathrm{p}=0.005)$ greater in those patients who progressed to develop ARDS $(n=24)$ than those who did not $(n=16)$ (Figure 3). The amiloride response was $7.6 \mathrm{mV}$ (95\% CL: 3.2, 13.4; $p=0.013)$ greater in those patients who progressed to develop ARDS than those who did not (Figure 3).

Those patients who died with ARDS $(n=23)$ had a non-significantly greater mNPD than survivors $(n=38)(-4.6 \mathrm{mV} ; 95 \% \mathrm{CL}:-9.7,0.3 ; \mathrm{p}=0.076)$ (Figure 3$)$. In the ARDS group, the difference in amiloride response between those who lived and those who died was $8.8 \mathrm{mV}$ (95\% CL: 2.9, $14.3 \mathrm{mV}$; $\mathrm{p}=0.0017)$ (Figure 3).

\section{Temporal changes in nasal potential difference}

Thirteen subjects who had NPD readings while at-risk for ARDS, underwent repeat measurement within 24 hours of the onset of ARDS (Figure 4). Maximum NPD was non-significantly increased (became more negative) by $-4.9 \mathrm{mV}$ (95\% CL: 11.3, -0.3; $p=0.12)$. The amiloride response was similar between both groups, differing by $0.23 \mathrm{mV}(95 \% \mathrm{CL}:-5.5,5.5 ; \mathrm{p}=0.94)$. Seven subjects had paired NPD measurements during ARDS and following ICU discharge (Figure 4). Maximum NPD decreased (became less negative) by $17.8 \mathrm{mV}$ (95\% CL: -22.4, -9.8; $\mathrm{p}=0.02)$. The difference in amiloride response was $3.0 \mathrm{mV}$ (95\% CL: -3.1, 10.9; $p=0.50)$. 


\section{Discussion}

We hypothesized that critically ill mechanically ventilated patients in the intensive care unit with a risk factor for the development of ARDS, would have a lower NPD (i.e. reduced sodium transport), and would be at greatest risk for ARDS development, and of death from ARDS. Our findings do not support this hypothesis. The findings of this study suggest that upper respiratory tract sodium channel activity is already increased in those patients who go on to develop ARDS, increases further during ARDS, and returns to normal after ARDS. NPD is not statistically different for controls and ARDS survivors.

Sodium transport in the nasal epithelium differs between those who do or do not develop ARDS, and although the result did not reach statistical significance, there was a trend towards greater NPD in ARDS patients who later progressed to death. Alveolar fluid clearance is down-regulated in $\mathrm{ARDS},{ }^{3}$ suggesting that the observed increase in sodium transport may be an attempt to overcome alveolar cellular injury by up-regulating the remaining sodium transport capability. It is possible that an electrical discordance exists between a relative healthy nasal epithelium, and a damaged alveolar epithelium, with elevated nasal sodium transport reflecting a pan-respiratory epithelial sodium transport response to an increase in extravascular lung water. NPD may be a biomarker of the requirement for upregulated alveolar sodium transport and a surrogate measure of increased extravascular lung water during periods of oedema which decreases with recovery. This would be consistent with a previous report of early increased extravascular lung water being predictive of the development of ARDS. ${ }^{22}$ This may be alternatively explained by several catecholamine-dependent and independent pathways that can upregulate vectorial sodium transport and alveolar fluid clearance and may be 
activated in patients at risk of developing ARDS or in patients with ARDS. These include: elevated levels of endogenous or exogenous catecholamines, elevated levels of glucocorticoids, and even elevated levels of thyroid hormone. ${ }^{23}$ Interestingly, the use of exogenous catecholamines did not seem to affect mNPD in this study.

It would be interesting to determine the effects of exogenous corticosteroid administration on NPD in ARDS, however unfortunately data on corticosteroid use was not collected. Furthermore, this study did not explore the temporal relationship between mNPD and indices of lung injury severity in ARDS. It would have been interesting to compare repeated measures of indices such as the Lung Injury Severity Score ${ }^{24}$ or the $\mathrm{PaO}_{2} / \mathrm{FiO}_{2}$ ratio to NPD over time.

The unexpected trend towards increased upper respiratory epithelial sodium transport during ARDS may help explain the negative findings of two previous large multi-centre trials of $\beta$ agonists in ARDS. ${ }^{25,26}$ Despite strong preclinical evidence demonstrating that $\beta$ agonists can upregulate alveolar sodium transport and enhance AFC,${ }^{27}$ these large trials did not show benefit. The present study suggests that ion transport mechanisms may already be upregulated in ARDS, perhaps in the presence of increased extravascular lung water (EVLW). Therefore, treatment with $\beta$ agonists may have been unsuccessful, as respiratory sodium transport was already maximally upregulated. A notable limitation is that EVLW was not directly measured in this study, and it remains for future studies to elucidate the exact relationship between NPD and EVLW in ARDS.

The funding period ended and the study was halted before the planned number of "at-risk" patients could be recruited. Despite an underpowered sample size, the results of this study suggest that increased NPD is a fair predictor of ARDS 
development. The predictive capacity of NPD for the development of ARDS found in this study (AUC $0.75[95 \% \mathrm{CL}: 0.59,0.89]$ ) is greater than previously reported values for non-ventilated subjects with bilateral infiltrates on a chest radiograph ${ }^{28}$ $\left(A \cup C=0.70^{29}\right)$, but less than a machine-learning approach ${ }^{30}$ and the Lung Injury Prediction Score $\left(0.80^{31}\right.$ and $0.84^{32}$ respectively).

The predictive capacity of NPD for death was modest $(A U C=0.60)$. Although a reduced rate of AFC has been associated with increased mortality in ARDS, the attributable mortality from ARDS may be surpassed by the co-morbid conditions which often co-exist in patients with ARDS. Further, the injury detected by NPD reflects only the degree of alveolar epithelial injury, discounting damage to the capillary bed as well as the presence or absence of shock.

Because NPD is a non-invasive bedside tool, it could be incorporated into future ARDS therapeutic trials to identify patients at high or low risk of developing the syndrome. It could also be used as a surrogate marker to track disease progression. However, the utility of NPD to predict ARDS will have to be validated further in a larger cohort and across more centres before this can become a reality.

In early 2020, the novel coronavirus SARS-CoV-2 (COVID-19 disease) rapidly progressed to the scale of a global pandemic. While the clinical course and pathophysiology of COVID-19 has yet to be fully elucidated, it is clear that progression to ARDS is a devastating consequence. ${ }^{33}$ Rapid, non-invasive bedside tools could help predict which patients do and do not progress to ARDS. The high specificity of increased NPD for ARDS development at a threshold of $-32.4 \mathrm{mV}$ suggests that it could be a useful tool to identify those who are unlikely to develop ARDS. This could allow prognostic enrichment through excluding these patients and focusing experimental treatments on a higher risk cohort. ${ }^{34,35}$ While further validation 
of NPD as a tool to predict ARDS development is needed, the data presented here suggest the value of NPD and the need for further study.

\section{Conclusion}

Increased NPD was a fair predictor of ARDS development in the at-risk group, but a modest predictor of ARDS mortality. Upper respiratory epithelial sodium transport increases before ARDS, is significantly greater during ARDS, and is not different from control values in survivors. This study demonstrates a physiological pattern of respiratory epithelial sodium transport in different states of health. Nasal potential difference may have value as a non-invasive surrogate measure of the physiological response to upregulate sodium transport in ARDS. 


\section{References}

1. Berthiaume $Y$, Matthay MA. Alveolar edema fluid clearance and acute lung injury. Respir Physiol Neurobiol 2007; 159(3): 350-9.

2. Matalon S, O'Brodovich $\mathrm{H}$. Sodium channels in alveolar epithelial cells: molecular characterization, biophysical properties, and physiological significance. Annu Rev Physiol 1999; 61: 627-61.

3. Ware LB, Matthay MA. Alveolar fluid clearance is impaired in the majority of patients with acute lung injury and the acute respiratory distress syndrome. Am J Respir Crit Care Med 2001; 163(6): 1376-83.

4. Mac Sweeney R, Fischer H, McAuley DF. Nasal potential difference to detect $\mathrm{Na}+$ channel dysfunction in acute lung injury. Am J Physiol Lung Cell Mol Physiol 2011; 300(3): L305-18.

5. Smith JJ, Welsh MJ. Fluid and electrolyte transport by cultured human airway epithelia. J Clin Invest 1993; 91(4): 1590-7.

6. Tarran R. Regulation of airway surface liquid volume and mucus transport by active ion transport. Proc Am Thorac Soc 2004; 1(1): 42-6.

7. Crandall ED, Matthay MA. Alveolar epithelial transport. Basic science to clinical medicine. Am J Respir Crit Care Med 2001; 163(4): 1021-9.

8. Knowles MR, Buntin WH, Bromberg PA, Gatzy JT, Boucher RC. Measurements of transepithelial electric potential differences in the trachea and bronchi of human subjects in vivo. Am Rev Respir Dis 1982; 126(1): 108-12.

9. Knowles MR, Carson JL, Collier AM, Gatzy JT, Boucher RC. Measurements of nasal transepithelial electric potential differences in normal human subjects in vivo. Am Rev Respir Dis 1981; 124(4): 484-90. 
10. Knowles M, Gatzy J, Boucher R. Increased bioelectric potential difference across respiratory epithelia in cystic fibrosis. N Engl J Med 1981; 305(25): 1489-95.

11. Barker PM, Gowen CW, Lawson EE, Knowles MR. Decreased sodium ion absorption across nasal epithelium of very premature infants with respiratory distress syndrome. J Pediatr 1997; 130(3): 373-7.

12. Helve O, Pitkanen OM, Andersson S, O'Brodovich H, Kirjavainen T, Otulakowski G. Low expression of human epithelial sodium channel in airway epithelium of preterm infants with respiratory distress. Pediatrics 2004; 113(5): 126772.

13. Sartori C, Allemann $\mathrm{Y}$, Duplain $\mathrm{H}$, et al. Salmeterol for the prevention of highaltitude pulmonary edema. N Engl J Med 2002; 346(21): 1631-6.

14. Betz T, Dehnert C, Bartsch P, Schommer K, Mairbaurl H. Does High alveolar fluid reabsorption prevent HAPE in individuals with exaggerated pulmonary hypertension in hypoxia? High Alt Med Biol 2015; 16(4): 283-9.

15. Maggiorini M, Brunner-La Rocca HP, Peth S, et al. Both tadalafil and dexamethasone may reduce the incidence of high-altitude pulmonary edema: a randomized trial. Ann Intern Med 2006; 145(7): 497-506.

16. Sartori C, Duplain H, Lepori M, et al. High altitude impairs nasal transepithelial sodium transport in HAPE-prone subjects. Eur Respir J 2004; 23(6): 916-20.

17. Egli M, Duplain H, Lepori M, et al. Defective respiratory amiloride-sensitive sodium transport predisposes to pulmonary oedema and delays its resolution in mice. J Physiol 2004; 560(Pt 3): 857-65.

18. Bernard GR, Artigas A, Brigham KL, et al. The American-European Consensus Conference on ARDS. Definitions, mechanisms, relevant outcomes, and clinical trial coordination. Am J Respir Crit Care Med 1994; 149(3 Pt 1): 818-24. 
19. The ARDS Definition Task Force. Acute respiratory distress syndrome: the Berlin definition. JAMA 2012; 307(23): 2526-33.

20. Matthay MA MC. Pulmonary edema and acute lung injury. Murray \& Nadel's Textbook of Respiratory Medicine. 5th ed. Philadelphia: Saunders / Elsevier; 2010: 2400.

21. Middleton PG, Geddes DM, Alton EW. Protocols for in vivo measurement of the ion transport defects in cystic fibrosis nasal epithelium. Eur Respir J 1994; 7(11): 2050-6.

22. LeTourneau JL, Pinney J, Phillips CR. Extravascular lung water predicts progression to acute lung injury in patients with increased risk. Crit Care Med 2012; 40(3): 847-54.

23. Matthay MA. Resolution of pulmonary edema. Thirty years of progress. Am J Respir Crit Care Med 2014; 189(11): 1301-8.

24. Murray JF, Matthay MA, Luce JM, Flick MR. An expanded definition of the adult respiratory distress syndrome. Am Rev Respir Dis 1988; 138(3): 720-3.

25. Gao Smith F, Perkins GD, Gates S, et al. Effect of intravenous beta-2 agonist treatment on clinical outcomes in acute respiratory distress syndrome (BALTI-2): a multicentre, randomised controlled trial. Lancet 2012; 379(9812): 229-35.

26. Matthay MA, Brower RG, Carson S, et al. Randomized, placebo-controlled clinical trial of an aerosolized beta(2)-agonist for treatment of acute lung injury. $A m \mathrm{~J}$ Respir Crit Care Med 2011; 184(5): 561-8.

27. Perkins GD, McAuley DF, Richter A, Thickett DR, Gao F. Bench-to-bedside review: beta2-agonists and the acute respiratory distress syndrome. Crit Care 2004; 8(1): 25-32. 
28. Levitt JE, Bedi H, Calfee CS, Gould MK, Matthay MA. Identification of early acute lung injury at initial evaluation in an acute care setting prior to the onset of respiratory failure. Chest 2009; 135(4): 936-43.

29. Soto GJ, Kor DJ, Park PK, et al. Lung injury prediction score in hospitalized patients at risk of acute respiratory distress syndrome. Crit Care Med 2016; 44(12): 2182-91.

30. Zeiberg D, Prahlad T, Nallamothu BK, Iwashyna TJ, Wiens J, Sjoding MW. Machine learning for patient risk stratification for acute respiratory distress syndrome. PLOS ONE 2019; 14(3): e0214465.

31. Trillo-Alvarez C, Cartin-Ceba R, Kor DJ, et al. Acute lung injury prediction score: derivation and validation in a population-based sample. Eur Respir J 2011; 37(3): 604-9.

32. Gajic O, Dabbagh O, Park PK, et al. Early identification of patients at risk of acute lung injury: evaluation of lung injury prediction score in a multicenter cohort study. Am J Respir Crit Care Med 2011; 183(4): 462-70.

33. Wu C, Chen X, Cai $\mathrm{Y}$, et al. Risk factors associated with acute respiratory distress syndrome and death in patients with coronavirus disease 2019 pneumonia in Wuhan, China. JAMA Internal Medicine 2020.

34. Mehta P, McAuley DF, Brown M, Sanchez E, Tattersall RS, Manson JJ. COVID-19: consider cytokine storm syndromes and immunosuppression. The Lancet 2020; 395(10229): 1033-4

35. Cavalli G, De Luca G, Campochiaro C, et al. Interleukin-1 blockade with highdose anakinra in patients with COVID-19, acute respiratory distress syndrome, and hyperinflammation: a retrospective cohort study. The Lancet Rheumatology 2020; 2(6): e325-e31. 
36. Vandenbroucke JP, von Elm E, Altman DG, et al. Strengthening the Reporting of Observational Studies in Epidemiology (STROBE): explanation and elaboration. PLOS Medicine 2007; 4(10): e297. 


\section{Figures}

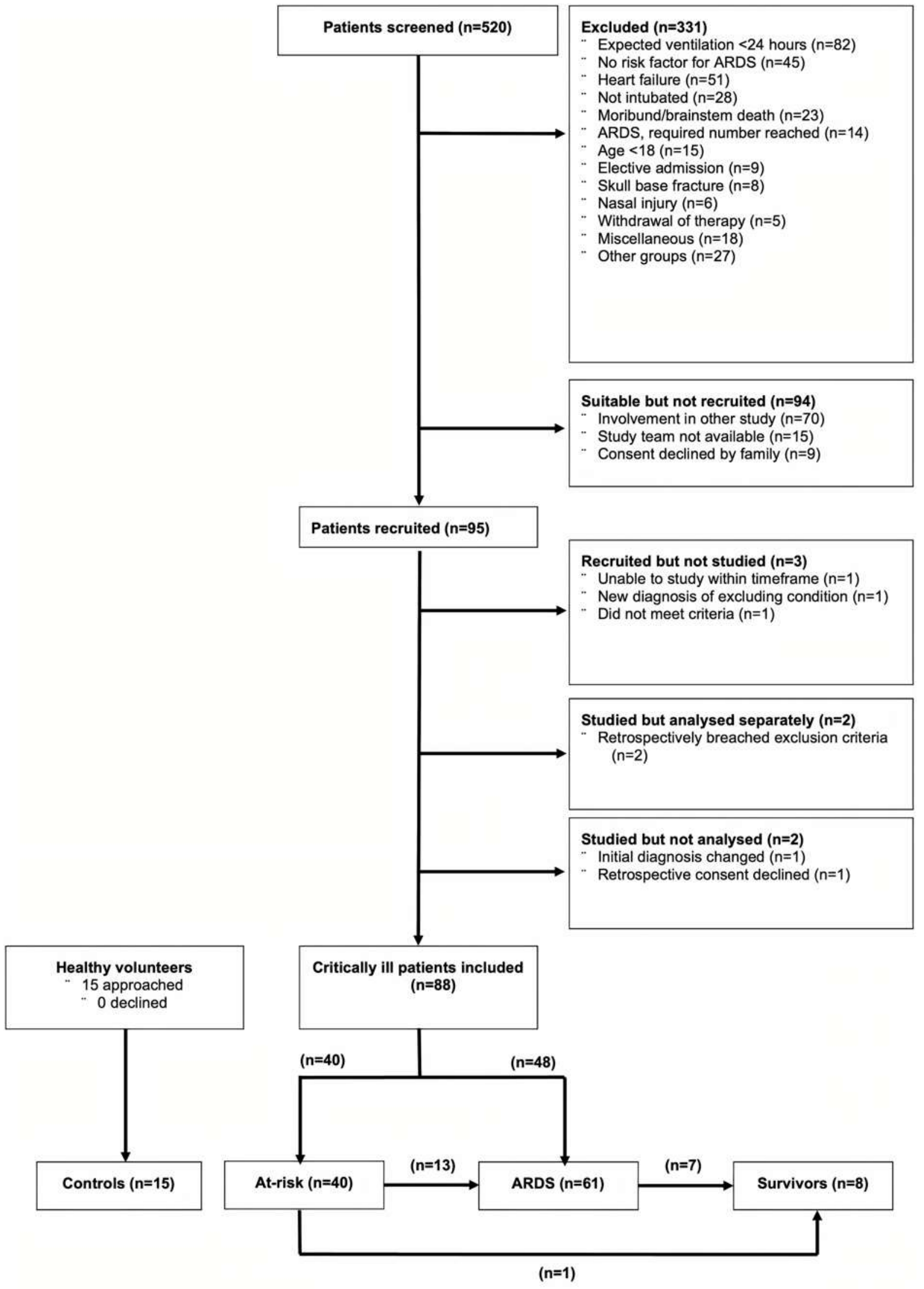


Figure 1: Flow diagram of patients screened, excluded, and included in this study. A total of 15 controls and 88 patients were recruited. 40 patients were recruited while "at-risk" for ARDS (having an ARDS risk factor but not meeting AECC/Berlin criteria for ARDS). The "ARDS" group consisted of 48 patients recruited with ARDS and 13 with ARDS who had previously had their NPD recorded while at-risk for ARDS. The "survivors" group consisted of 8 patients recovering on the ward after ARDS, 7 of whom who had their NPD previously recorded while they had a diagnosis of ARDS, and 1 of whom who had their NPD previously recorded while at-risk for ARDS. Of note, this 1 patient did develop ARDS but did not have NPD measurements taken at that time point, and therefore bypasses the ARDS group in this diagram. This diagram follows the STROBE ${ }^{36}$ guidelines for improving the reporting of observational studies. 


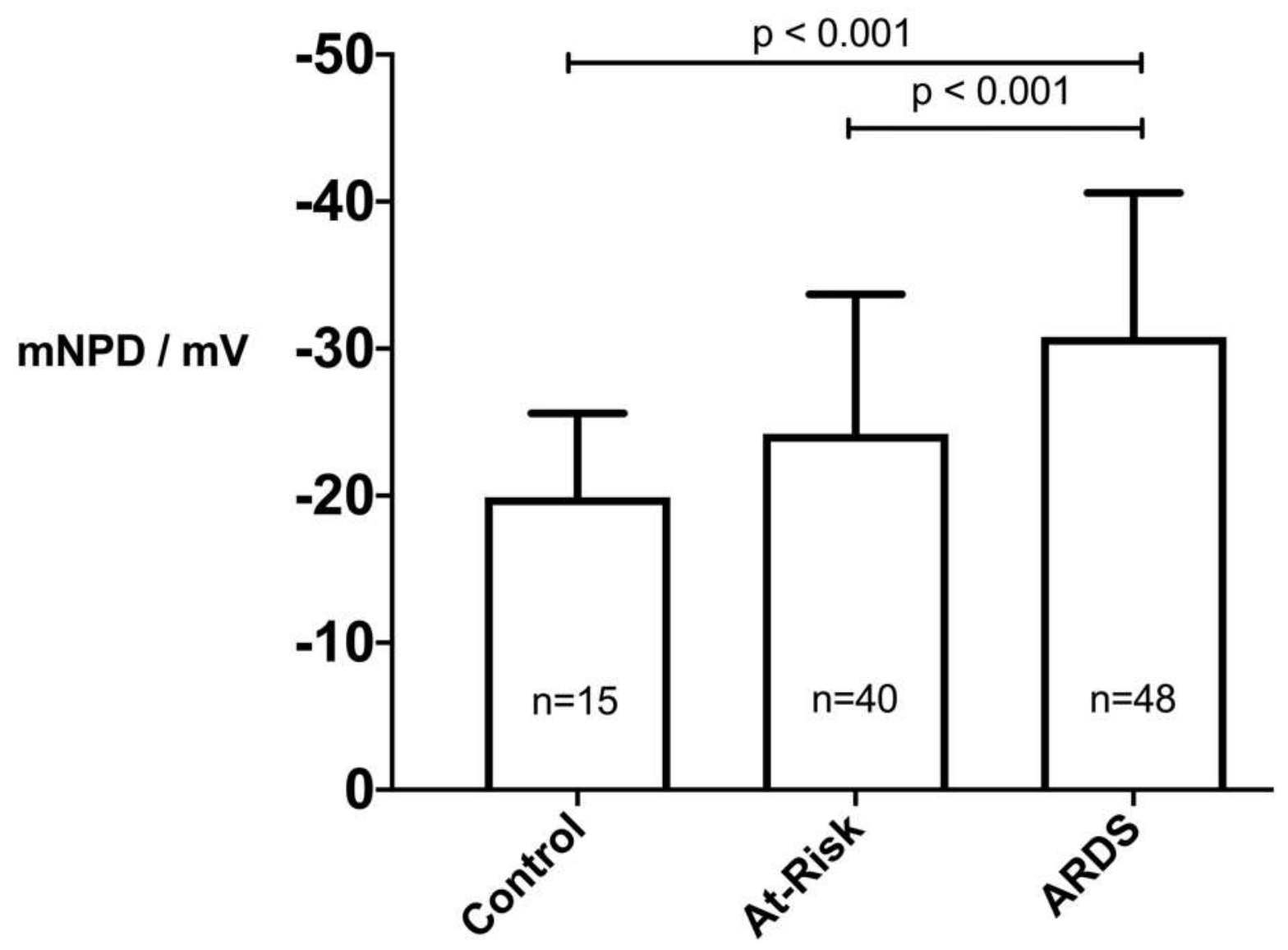

Figure 2: Inter-group comparisons of maximum NPD in control, at-risk, and ARDS subjects. Data are mean (SD). Bootstrapped 95\% confidence limits using the DunnSidak adjustment for multiplicity reached nominal limits of $98.3 \%$. Differences between the at-risk group and the ARDS group (98.3\% CL 1.77, 10.93), as well as between the control group and the ARDS group reached statistical significance $(98.3 \% \mathrm{CL} 4.27,16.79)$. The control group and the overall at-risk group were not significantly different $(98.3 \% \mathrm{CL}-1.90,10.73)$. 


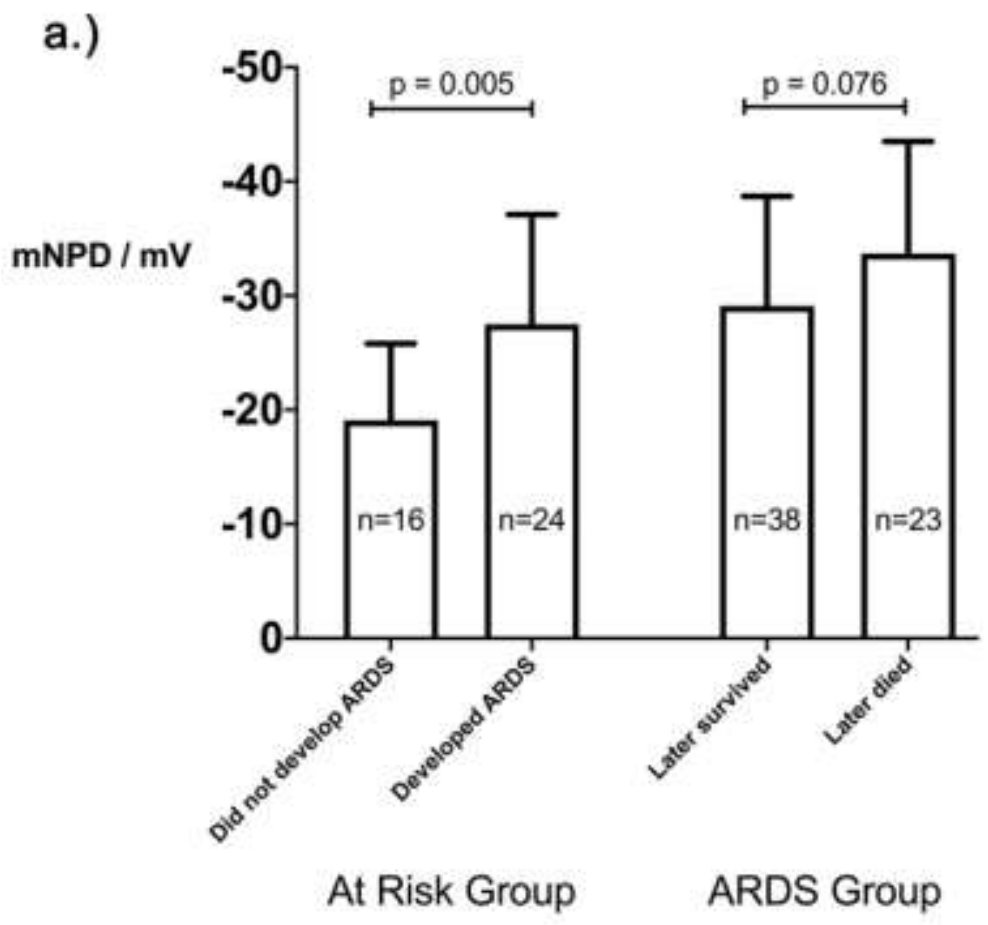

b.)

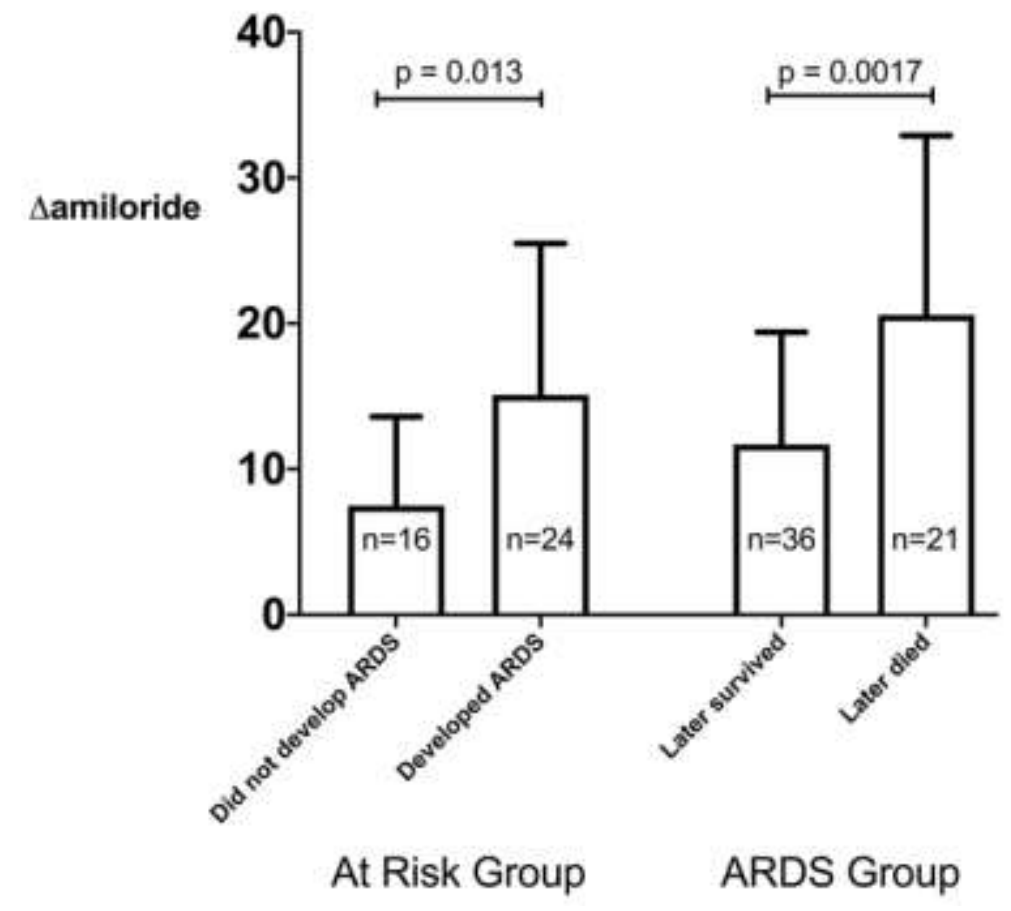

Figure 3: Intra-group comparisons for subjects who did or did not develop ARDS, and in ARDS subjects who went on to survive or went on to die. Data are mean (SD). Figure 3a shows maximum NPD (mNPD). Figure $\mathbf{3 b}$ shows the amiloride response. Four NPD measurements in the ARDS group did not include the amiloride response. 


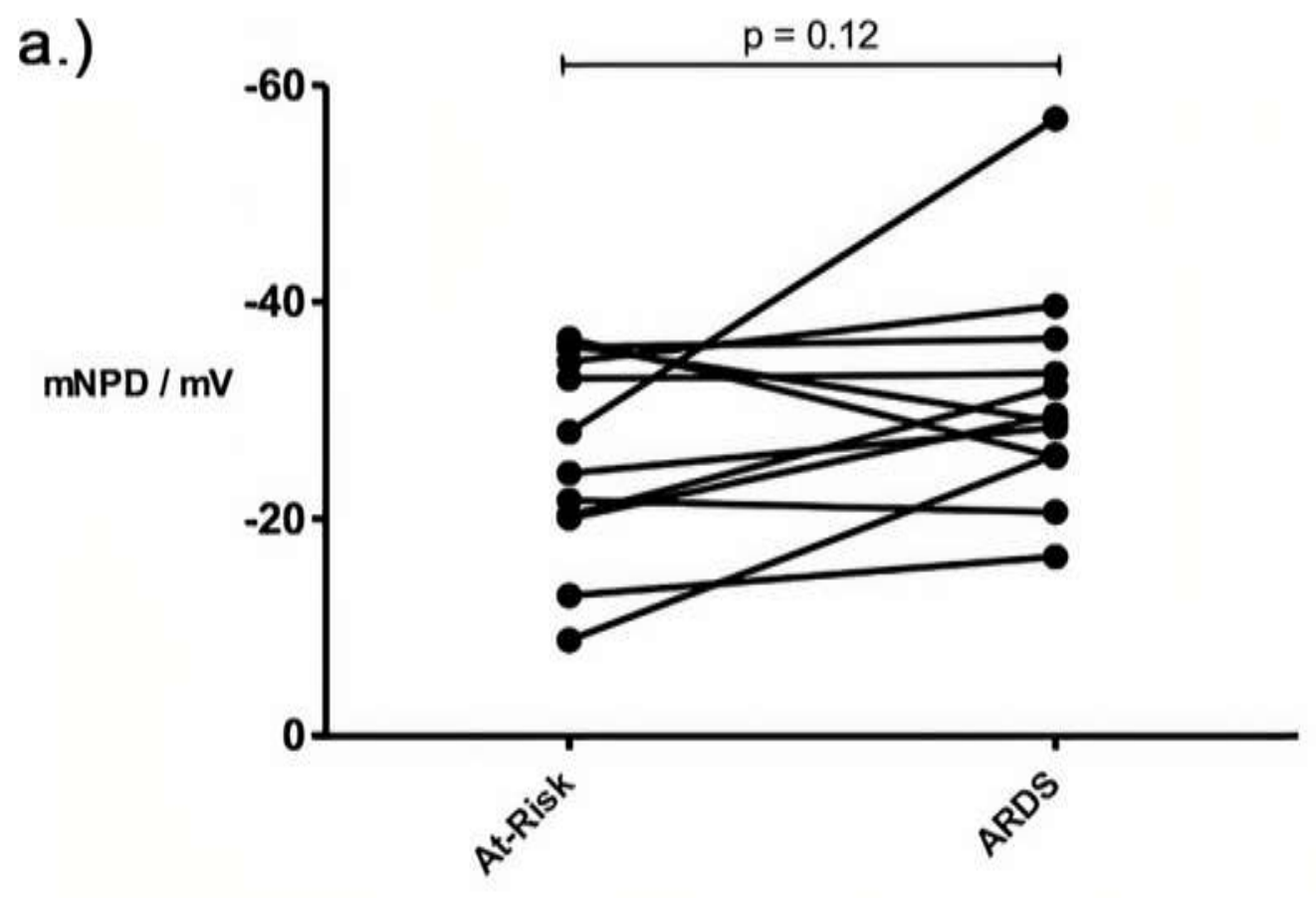

b.)

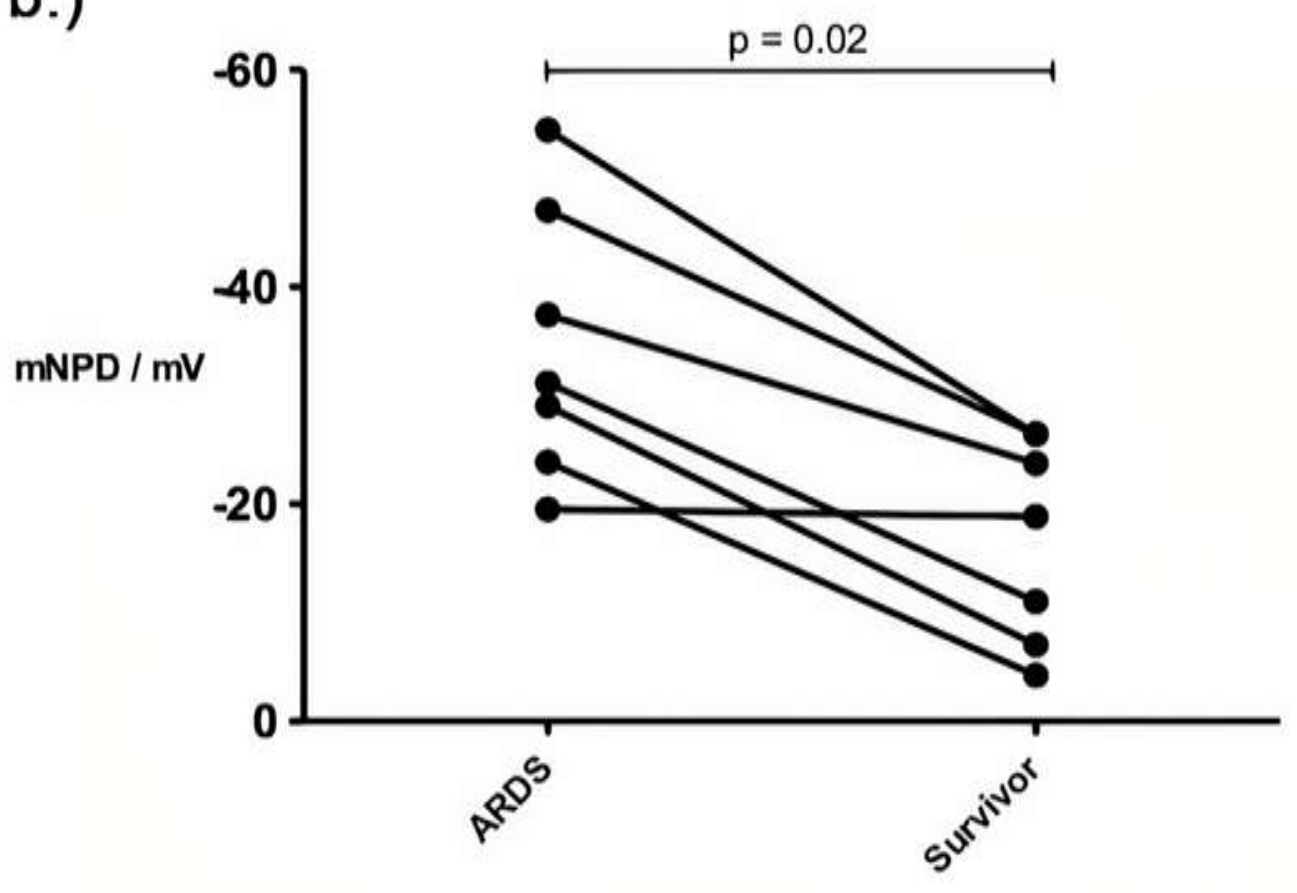

Figure 4: Sequential values of maximum nasal potential difference (mNPD). Figure 4a shows sequential values for those subjects initially at-risk for ARDS, and later with ARDS. Figure $4 \mathrm{~b}$ shows sequential values for those subjects with ARDS, and later when recovering outside the intensive care unit. 
Tables

\begin{tabular}{|c|c|c|c|c|}
\hline & At Risk & ARDS & Survivors & Controls \\
\hline Number of measurements & 40 & 61 & 8 & 15 \\
\hline Age (years) & 50.6 & 58.5 & 59.1 & 30.3 \\
\hline Male (\%) & 67.5 & 68.9 & 87.5 & 73.3 \\
\hline \multicolumn{5}{|l|}{ ARDS risk factor (\%) } \\
\hline pneumonia & $3(7.5 \%)$ & $15(24.6 \%)$ & $1(12.5 \%)$ & \\
\hline aspiration & $4(10 \%)$ & $8(13.1 \%)$ & & \\
\hline one lung ventilation & 0 & $4(6.6 \%)$ & $1(12.5 \%)$ & \\
\hline chest trauma & 0 & $2(3.3 \%)$ & $1(12.5 \%)$ & \\
\hline non-pulmonary sepsis & $11(27.5 \%)$ & $12(19.7 \%)$ & $4(50 \%)$ & \\
\hline massive transfusion & $6(15 \%)$ & $10(16.4 \%)$ & $1(12.5 \%)$ & \\
\hline shock & $7(10 \%)$ & $1(1.7 \%)$ & & \\
\hline subarachnoid & $5(12.5 \%)$ & 0 & & \\
\hline \multicolumn{5}{|l|}{ haemorrhage } \\
\hline traumatic brain injury & $9(22.5 \%)$ & $6(9.8 \%)$ & & \\
\hline pancreatitis & $1(2.5 \%)$ & $2(3.3 \%)$ & & \\
\hline trauma & $4(10 \%)$ & $3(4.9 \%)$ & $1(12.5 \%)$ & \\
\hline APACHE II * & $15.2(7.2)$ & $18.9(6.6)$ & & \\
\hline $\mathrm{Vt} / \mathrm{Kg}(\mathrm{ml} / \mathrm{kg})^{*}$ & $8.3(1.4)$ & $8.5(1.8)$ & & \\
\hline Ppeak $\left(\mathrm{cm} \mathrm{H} \mathrm{H}_{2} \mathrm{O}\right)$ * & $19(4.8)$ & $21.1(4.4)$ & & \\
\hline PEEP $\left(\mathrm{cm} \mathrm{H}_{2} \mathrm{O}\right)$ * & $4.9(1.6)$ & $7.2(2.3)$ & & \\
\hline $\mathrm{PaO}_{2} / \mathrm{FiO}_{2}$ * $(\mathrm{kPa})$ & $38.9(13.3)$ & $24.5(8.7)$ & & \\
\hline $\mathrm{pH}$ & $7.38(0.09)$ & $7.37(0.07)$ & & \\
\hline fluid balance $(\mathrm{ml})$ * & $3628(3474)$ & $5844(7376)$ & & \\
\hline antimicrobials * & $23(57.5 \%)$ & $52(85.2 \%)$ & & \\
\hline inotropes / vasopressors* & $24(60.0 \%)$ & $29(47.5 \%)$ & & \\
\hline $\mathrm{CRP}(\mathrm{mg} / \mathrm{L})$ & $89.6(97)$ & $184(144.2)$ & & \\
\hline $\operatorname{WCC}\left(\times 10^{9} / L\right)$ & $13.5(7.6)$ & $14.8(9.8)$ & & \\
\hline
\end{tabular}

Table 1: Baseline characteristics.

Some subjects had more than one risk factor for the development of ARDS. Groups are not mutually exclusive. The "shock" group included a variety of non-sepsis conditions associated with hypotension, such as post-cardiac arrest syndrome, cardiogenic shock, drug overdose, and hypovolaemic shock. APACHE II, acute physiology and chronic health evaluation II; Vt / Kg, tidal volume per kilogram predicted body weight; PEEP, positive end expiratory pressure; $\mathrm{PaO}_{2}$, partial pressure of oxygen; $\mathrm{FiO}_{2}$, fraction of inspired oxygen; $\mathrm{CRP}, \mathrm{C}$ reactive protein; WCC, white cell count. * Variables evaluated in the logistic model for the development of ARDS in the at-risk group, and death in the ARDS group, were chosen based on previous associations for the development of these outcomes. 


\begin{tabular}{|c|c|c|c|c|}
\hline \multicolumn{3}{|c|}{ At-Risk } & \multicolumn{2}{|l|}{ ARDS } \\
\hline Predictor & $\begin{array}{l}\text { Odds ratio for } \\
\text { ARDS } \\
\text { development }\end{array}$ & $95 \% \mathrm{CL}$ & $\begin{array}{l}\text { Odds ratio for } \\
\text { mortality }\end{array}$ & $95 \% \mathrm{CL}$ \\
\hline $\begin{array}{l}\text { Maximum NPD } \\
(-1 \mathrm{mV})\end{array}$ & 0.90 & $0.81-0.97$ & 0.95 & $0.90-1.01$ \\
\hline $\begin{array}{l}\text { Fluid balance } \\
(1 \mathrm{~L})\end{array}$ & 1.00 & $1.00-1.00$ & 1.00 & $1.00-1.00$ \\
\hline $\begin{array}{l}\text { Vasoactive } \\
\text { therapy (+/-) }\end{array}$ & 2.96 & $0.84-11.1$ & 2.24 & $0.80-6.60$ \\
\hline $\begin{array}{l}\mathrm{Vt} / \mathrm{Kg} \\
(1 \mathrm{~mL} / \mathrm{kg})\end{array}$ & 1.31 & $0.83-2.20$ & 0.97 & $0.72-1.29$ \\
\hline $\begin{array}{l}\text { Antimicrobial } \\
\text { therapy }(+/-)\end{array}$ & 1.63 & $0.47-5.81$ & 0.49 & $0.09-2.05$ \\
\hline $\begin{array}{l}\mathrm{PaO}_{2} / \mathrm{FiO}_{2} \\
(1 \mathrm{kPA})\end{array}$ & 0.99 & $0.95-1.04$ & 0.96 & $0.90-1.02$ \\
\hline $\begin{array}{l}\text { PEEP } \\
\left(1 \mathrm{cmH}_{2} \mathrm{O}\right)\end{array}$ & 1.03 & $0.71-1.55$ & 1.02 & $0.82-1.28$ \\
\hline $\begin{array}{l}\text { APACHE II } \\
\text { (1 point) }\end{array}$ & 1.01 & $0.93-1.11$ & 1.04 & $0.97-1.13$ \\
\hline $\begin{array}{l}\text { Peak airway } \\
\text { pressure } \\
\left(1 \mathrm{cmH}_{2} \mathrm{O}\right)\end{array}$ & 1.00 & $0.88-1.15$ & 1.07 & $0.95-1.22$ \\
\hline
\end{tabular}

Table 2: Odds ratios (OR) of variables associated with the development of ARDS in the at-risk group and death in the ARDS group as determined by binary logistic regression. For all continuous variables, the reported $\mathrm{OR}$ is associated with a oneunit increment; the associated increment is provided in brackets below each relevant predictor. Antimicrobial therapy and vasoactive therapy are binary variables, and the reported OR is associated with use of the indicated therapy. 


\begin{tabular}{|l|l|l|r|r|r|r|}
\hline & \multicolumn{3}{|c|}{ Maximum } & NPD & \multicolumn{2}{c|}{$\begin{array}{c}\text { Amiloride } \\
(\mathbf{m V})\end{array}$} \\
\hline Group & Number & Mean & \multicolumn{1}{c|}{ SD } & Number & Mean & SD \\
\hline Controls & $\mathrm{n}=15$ & -19.9 & 5.7 & $\mathrm{n}=15$ & 12.9 & 8.3 \\
\hline & & & & & & \\
\hline At Risk & $\mathrm{n}=40$ & -24.2 & 9.5 & $\mathrm{n}=40$ & 12.1 & 9.6 \\
\hline No ARDS & $\mathrm{n}=16$ & -19.1 & 6.7 & $\mathrm{n}=16$ & 7.5 & 6.1 \\
\hline ARDS & $\mathrm{n}=24$ & -27.5 & 9.6 & $\mathrm{n}=24$ & 15.1 & 10.4 \\
\hline & & & & & & \\
\hline ARDS & $\mathrm{n}=61$ & -30.8 & 9.8 & $\mathrm{n}=44$ & 15.0 & 10.5 \\
\hline Lived & $\mathrm{n}=38$ & -29.1 & 9.6 & $\mathrm{n}=36$ & 11.7 & 7.9 \\
\hline Died & $\mathrm{n}=23$ & -33.7 & 9.8 & $\mathrm{n}=21$ & 20.6 & 12.3 \\
\hline & & & & & & \\
\hline Survivors & $\mathrm{n}=8$ & -15.6 & 9.3 & $\mathrm{n}=6$ & 12.7 & 2.8 \\
\hline & & & & & & \\
\hline $\begin{array}{l}\text { Repeat } \\
\text { Readings }\end{array}$ & & & & & & \\
\hline At Risk & $\mathrm{n}=13$ & -27.7 & 11.0 & $\mathrm{n}=13$ & 14.8 & 11.9 \\
\hline ARDS & $\mathrm{n}=13$ & -32.6 & 11.0 & $\mathrm{n}=13$ & 15.0 & 11.1 \\
\hline & & & & & & \\
\hline ARDS & $\mathrm{n}=7$ & -34.6 & 12.5 & $\mathrm{n}=6$ & 15.6 & 10.3 \\
\hline Survivor & $\mathrm{n}=7$ & -16.8 & 9.3 & $\mathrm{n}=6$ & 12.7 & 2.8 \\
\hline
\end{tabular}

Table 3: Nasal potential difference values.

Patients undergoing NPD measurements when both at-risk and during ARDS were included in intra-group comparisons (at-risk group: did versus did not develop ARDS) but had their ARDS measurement excluded from inter-group comparisons (at-risk group versus ARDS group). This exclusion was made in order to improve statistical integrity for inter-group analyses. (i.e. a patient measured whilst at risk, and remeasured later after developing ARDS, becomes a repeated measure rather than a distinct subject). This accounts for the smaller number of ARDS patients in intergroup analyses than intra-group analyses. 